\title{
Democracia, controle civil e gastos militares no Pós-Guerra Fria: uma análise realista
}

\section{Democracy, civilian control and military expenditures after the Cold War: a realist analysis}

Thomas Ferdinand Heye*

\section{Resumo}

O objetivo deste artigo é o de apresentar uma análise realista dos gastos militares no Pós-Guerra Fria. Para tanto, argumentaremos que a demanda por gastos militares é uma propriedade estrutural do sistema internacional cujo comportamento é afetado por fatores presentes na esfera política doméstica dos Estados, mais especificamente, por regimes democráticos e pelo controle civil sobre as forças armadas. Para testar nossas hipóteses utilizamos o recurso econométrico de análise dinâmica de dados em painel com Métodos de Momentos Generalizados em 61 países no período de 1990 a 1998.

Palavras-chaves: Democracia; Controle Civil; Gastos Militares; Neorealismo; Análise quantitativa; Política Comparada

\section{Abstract}

The objective of this article is to present a realist analysis of military expenditures after the Cold War. For this, we argue that the demand for military expenditures is a structural propriety of the international system that is influenced by factors present in the domestic political sphere of the State, specifically by democratic regimes and by the civilian control over the armed forces. To test our hypothesis we used the econometric resource of panel data dynamic analysis with Generalized Method of Moments in 61countries in the period from 1990 to 1998.

Key words: Democracy; Civilian Control; Military Expenditures; Neorealism; Quantitative Analysis; Comparative Politics

\footnotetext{
* Professor do Instituto de Estudos Estratégicos (INEST) da Universidade Federal Fluminense. E-mail: theye@id.uff.br
} 


\section{Introdução}

O ponto de partida para este artigo encontra-se na observação de um fenômeno que pode ser definido como extraordinário na longa história do século vinte: a queda significativa dos gastos militares mundiais na primeira metade da década de 90. A tendência de declínio no montante dos recursos destinados à defesa já era observada no final dos anos 80 e a partir de 1991, a diminuição dos gastos militares mundiais veio a ganhar ainda mais ímpeto. Contudo, a partir de 1998 os gastos militares mundiais voltaram novamente a aumentar. Assim, o foco deste artigo será no período de 1990 a 1998, mirando especificamente o fenômeno inédito da diminuição dos gastos militares mundiais e os seus determinantes políticos¹.

A análise do comportamento dos gastos militares nesse período proporcionará importantes subsídios para abordar questões presentes no debate teórico contemporâneo na disciplina de Relações Internacionais. Em particular, este artigo focalizará o problema de nível de análise, ou seja, a necessidade de convergir as dimensões externa e doméstica dos Estados em estudos de Relações Internacionais. A abordagem tradicional para o problema de nível de análise em Relações Internacionais inicia-se com o artigo pioneiro de J.D. Singer publicado em 1961. Segundo Singer, o problema de nivel de análise consiste em escolher entre os níveis micro ou macro, ou seja, "to focus upon the parts or upon the whole, upon the components or upon the system". Singer identificou dois niveis de análise em Relações Internacionais: o sistema internacional e os subsistemas nacionais.

O problema de nível de análise permaneceu na agenda teórica das Relações Internacionais conforme apontado por Buzan (1995), inclusive no Brasil. Neste sentido, por exemplo, as obras de Alves (2002 e 2007) exploram a problemática do nivel de análise em relação à política externa brasileira durante o período da Segunda Guerra Mundial e da Guerra da Coréia.

Através desta iniciativa de fazer convergir as dimensões externa e doméstica do Estado procuraremos contribuir para superar uma das limitações presentes no pensamento teórico realista das Relações Internacionais. Como Krasner (1992) ressalta, a principal corrente teórica das Relações Internacionais - o realismo - jamais confrontou diretamente a questão acerca do impacto dos regimes políticos doméstico dos Estados em relação à política internacional (e viceversa) - a não ser para enfatizar que estes não possuíam qualquer relevância.

Em suma, argumentarei que a demanda por gastos militares é uma propriedade estrutural do sistema internacional, cujo comportamento no pós-Guerra Fria é afetado por variáveis presentes na esfera política doméstica dos Estados. O objetivo desta iniciativa é o de providenciar uma análise sistemática e de caráter empírico do comportamento dos gastos militares nos anos 90 e de contribuir no esforço para superar as limitações decorrentes do problema de nível de análise presente na perspectiva neorealista da política internacional ao não incluir em suas análises as esferas domésticas do Estado, se limitando ao nível sistêmico. Como desdobramento, para os neorealistas, o processo de alocação de recursos públicos ocorre em um cenário doméstico desprovido de conflitos e disputas inerentes às preferências da sociedade

1 C.F www.sipri.org e Daniel P Hewitt. (1996), "Military Expenditures 1972-1990: The Reasons Behind the Post-1985 Fall in World Military Spending." Public Budgeting and Financial Management Vol. 7, n. 4. 
vis-à-vis às do Estado. E será justamente neste ponto que verificaremos a importância de regimes políticos e do controle civil sobre os militares.

Para testar nossas hipóteses iremos nos valer do recurso econométrico de análise dinâmica de dados em painel com Métodos de Momentos Generalizados (Generalised Method of Moments - GMM) em relação a 61 países ao longo do período de 1990 a 1998. Os resultados obtidos corroboram o argumento central de que o tipo de regime político e o controle civil sobre as forças armadas são fatores importantes para se compreender o comportamento dos gastos militares.

\section{Gastos militares no Pós-Guerra Fria}

Gastos militares são realizados pelos Estados com vistas à um fenômeno político externo, o fenômeno da guerra. Contudo, a obtenção e a alocação de recursos públicos no setor de defesa consistem de um fenômeno político doméstico. Portanto, gastos militares serão capazes de apreender ambas as dimensões do Estado e também serão capazes de apreender os dois níveis de análise presentes no pensamento realista contemporâneo: o sistêmico e o doméstico.

A investigação acerca dos gastos militares no cenário internacional do pós-Guerra Fria será particularmente propícia para o meu objetivo central em fazer convergir as dimensões sistêmica e doméstica do Estado. Em primeiro, no período analisado, entre 1990 e 1998, o cenário estratégico irá se revelar atipicamente pacífico. Como desdobramento, para utilizar um termo clausewitziano, será neste contexto que podemos suspender as brumas da guerra que nublam a perspectiva realista em relação aos fatores políticos domésticos dos gastos militares. Em segundo, será a primeira vez na história que o núcleo do sistema internacional será constituído exclusivamente por países democráticos e de capitalismo avançado. Como desdobramento destes fatores, verifica-se no pós-Guerra Fria a emergência de uma ordem mundial com fortes marcos liberais em suas dimensões política e econômica.

Em relação aos gastos militares, ao contrário do período da Guerra Fria, no qual os gastos militares mundiais apresentaram somente um comportamento, o de escalada, no pós-Guerra Fria verifica-se a diminuição dos gastos militares mundiais agregados.

A explicação consensual para o declínio dos gastos militares mundiais é de que as reduções substanciais feitas pelos países desenvolvidos em seus respectivos orçamentos militares ocorreram em função do fim da Guerra Fria, consequência direta da diminuição do grau de ameaça resultante do desmembramento da União Soviética e da dissolução do Pacto de Varsóvia. Todavia, o fim da União Soviética e a emergência da nova ordem mundial liberal sozinhos - não são uma resposta satisfatória para a decisão de um grande número de países em vias de desenvolvimento também reduzirem os seus gastos militares. Desta forma, para compreender o comportamento dos gastos militares individuais dos países no pós-Guerra Fria é necessário analisar também a dimensão doméstica dos Estados.

Neste sentido, o comportamento heterogêneo dos gastos militares individuais no pósGuerra Fria decorre do fato de que as pressões da nova ordem mundial liberal que emergiu nos anos 90 não se revelaram tão determinantes como se acreditava. Estas pressões de cunho liberal (ou neoliberal) da nova ordem mundial não representavam uma totalidade coerente como é 
frequentemente assumido, constituindo mais um manancial de instituiç̧ões, ideias e prescrições de políticas públicas dos quais os Estados poderiam fazer escolhas dependendo de condições políticas, econômicas, sociais, históricas e institucionais vigentes. Entretanto, o ponto a ser destacado aqui é de que os Estados não são impotentes diante da ascensão do neoliberalismo no pós-Guerra Fria. Neste sentido, Campbell e Pedersen (2001) destacam que Estados podem bloquear, adaptar, mediar e em alguns casos até mesmo reverter tendências neoliberais. Em outras palavras, Estados irão filtrar aquelas ideias, instituições e prescrições de políticas de cunho neoliberal através de suas instituições domésticas e refletirão os interesses destes.

Desta forma, os agentes encarregados dos Estados não estão limitados somente a enfrentar as pressões da nova ordem mundial liberal que emergiu no pós-Guerra Fria. Estes mesmos agentes também enfrentam pressões da esfera doméstica do Estado. Governantes estão cientes de que o tecido do Estado pode ser destruído não somente por forças externas, mas também por forças internas. Logo, para permanecerem no poder, estes agentes têm que administrar ao mesmo tempo as restrições impostas pelas dimensões externa e interna.

\section{Os determinantes políticos dos gastos militares}

Para investigar esta diversidade de comportamentos em relação aos gastos militares no pós-Guerra Fria, inicialmente é necessário responder a pergunta crucial de porquê Estados investem seus escassos recursos na forma de gastos militares. Para tanto, à luz da teoria da política internacional de Waltz (1979), argumentamos que a demanda por gastos militares é uma propriedade inerente da estrutura do sistema internacional. Ou seja, em um sistema internacional anárquico, no qual não há nenhuma autoridade supranacional, nada impede um Estado de agredir outro. Como desdobramento, todos os Estados, independente destes serem desenvolvidos ou não, possuem a mesma necessidade fundamental em assegurar a sua sobrevivência. Em outras palavras, a necessidade de sobrevivência é um denominador comum a todos os Estados do sistema internacional.

Entretanto, para Waltz (1979), o conceito de anarquia não é somente mais uma característica do cenário internacional. A anarquia constitui o mito de origem para a cosmogonia que este autor desenvolve em sua teoria de política internacional. De acordo com Waltz (1979), o sistema internacional anárquico surgiu assim que unidades políticas independentes começaram a interagir. Como desdobramento, a lógica da anarquia requeria que os agentes destas unidades políticas procurassem cursos de ação que thes permitiriam assegurar a sua sobrevivência, que, por sua vez, simultaneamente, acabava por reproduzir a estrutura anárquica do sistema internacional de maneira não intencional. Assim, conforme Wendt (1987) ressalta, os Estados seriam tanto as unidades constitutivas do sistema político internacional como também os responsáveis pela fundação de sua estrutura. Desta forma, Waltz (1979) define o sistema internacional como "composto de uma estrutura e de unidades que interagem". A estrutura, por sua vez, é caracterizada por somente dois componentes: 1) o princípio de ordenamento anárquico do sistema internacional e 2) a distribuição dos recursos de poder entre as unidades do sistema internacional. 
Em relação ao primeiro componente, o princípio de ordenamento anárquico do sistema internacional, é importante ressaltar que no pensamento teórico de Waltz anarquia, como Ruggie (1986) destaca, constituiria a estrutura profunda (deep structure) do sistema internacional. Para Waltz (1979), a estrutura do sistema é tão poderosa que irá gerar padrões de comportamentos similares entre os diferentes tipos de unidades. Nas palavras do autor, "a lógica da anarquia prevalece independentemente se o sistema é composto de tribos, nações, firmas oligopolistas ou gangues de rua". Como desdobramento da lógica de sobrevivência imposta pela anarquia, Waltz (1979) irá afirmar que as unidades políticas que constituem o sistema internacional serão submetidas às pressões de socialização e de competição.

A socialização seria decorrente das demonstrações de sucesso obtidas por algumas das unidades políticas, que por sua vez estimularia as demais unidades a emularem os exemplos de maior êxito. Por exemplo, as nações asiáticas que não foram colonizadas, como o Japão, Tailândia e China tiveram que adotar rapidamente características do modelo de Estado europeu para evitarem serem subjugadas pelo poderio deste. Como afirma Waltz (1979), "a justaposição dos Estados promove a sua igualdade através das desvantagens que emergem do fracasso em adotar práticas de sucesso".

Já no que se refere à competição entre as unidades, Waltz (1979) irá argumentar que uma vez que estas começam a interagir, a estrutura do sistema internacional exercerá uma forte influência no seu desenvolvimento. Waltz (1979) teoriza que o princípio ordenador da anarquia gera um ambiente competitivo. Estados, de acordo com esta perspectiva, não teriam outra alternativa a não ser competirem entre si. Este aspecto seria decorrente das pressões exercidas pela arena internacional anárquica que requer que os estados elaborem soluções próprias (selfhelp) para seus problemas. Desta forma, na ausência de uma instituição central para policiar soluções cooperativas, Estados não teriam alternativas a não ser assumir que estão operando em um sistema antagonístico ou ao menos competitivo. Assim, as próprias ações dos Estados acabam por reproduzir a característica competitiva do sistema. Waltz (1979) evidencia a lógica competitiva da anarquia e desenvolve a sua teoria do Estado lastreando-a na premissa de que o sistema internacional é "uma esfera competitiva".

Em um sistema competitivo, Estados não possuem outra alternativa a não ser a de tentar igualar qualquer desenvolvimento ou progresso que ocorra em outros Estados. O Estado que falhar em acompanhar os desenvolvimentos obtidos por outros ficará, de maneira inexorável, para trás e consequentemente se tornará mais vulnerável. Desta forma, qualquer avanço em um Estado será rapidamente copiado por outros. Como Waltz (1979) observa, já que Estados imitam uns aos outros, é possível predizer que "Estados irão apresentar características comuns entre os competidores". Neste sentido, por exemplo, "as armas dos maiores competidores e até mesmo as suas estratégias irão se assemelhar no mundo inteiro". Este argumento não se limita somente à esfera militar, incluindo também a dimensão econômica. O fracasso em adotar práticas comerciais de sucesso irá originar Estados não competitivos e, portanto, sem êxito no sistema internacional anárquico.

Desta forma, enquanto permanecer inalterado a condição anárquica do sistema internacional, Estados continuarão a buscar meios que garantam a sua sobrevivência como unidades políticas autônomas e, logo, soberanas. Os investimentos em recursos de defesa são 
um dos meios que os Estados possuem para se defender de agressões por parte de outros Estados. À guisa de síntese, a razão que justifica a alocação de parte dos escassos recursos do Estado para a sua defesa encontra-se na clássica passagem de uma obra anterior de Waltz (1965), que optamos em manter no original:

\footnotetext{
"With many states, with no system of law enforceable among them, with each state judging its grievances and ambitions according to the dictates of its own reason or desire - conflict, sometimes leading to war is bound to occur. To achieve a favorable outcome from such a conflict a state has to rely on its own devices, the relative efficiency of which must be its constant concern".
}

Em suma, a perspectiva teórica de Waltz possui como axioma a necessidade de sobrevivência do Estado. Este aspecto representa uma inovação em relação ao pensamento realista clássico. Se economistas definem interesses em termos de riqueza e partem da premissa da maximização de utilidade, os realistas clássicos irão definir interesses em termos de poder e vários destes autores irão se valer do paralelo com a economia no que se refere ao objetivo primário do Estado em maximizar o seu poder. Waltz, por sua vez, irá enfatizar que o objetivo primário do Estado é o de maximizar a sua segurança, ou seja, a necessidade de sobrevivência do Estado é um denominador comum a todos países. Todavia, a principal lacuna na teoria de política internacional de Waltz encontra-se na ausência da inclusão de fatores políticos domésticos. Neste sentido é também importante ressaltar que a política não se limita a uma simples disputa sobre a alocação de recursos. Neste sentido, caso um Estado procure aumentar os níveis de recursos extraídos de sua sociedade pode se deparar com reações negativas por parte dela. Os motivos para tanto podem variar desde da utilidade econômica percebida até o senso de justiça minado pelas novas preferências do Estado.

Como desdobramento, a razão para que Estados invistam recursos em meios de defesa não se limita somente à esfera externa. As ameaças para o Estado podem também possuir origem doméstica. Guerras de secessão, guerras civis e revoluções são algumas das ameaças que devem a sua origem a motivos essencialmente internos ao Estado. Neste sentido, é importante ressaltar que não estamos nos referindo a protestos populares e "quebra-quebras" em geral. Estes são erráticos, frequentemente espontâneos e de intensidade relativamente baixa, não constituindo uma ameaça imediata ao Estado. As ameaças domésticas ao Estado são aquelas nas quais se verifica uma divisão profunda na sociedade, acompanhado de uma radicalização nas posições das partes envolvidas e a crença por ao menos de uma das facções de que os instrumentos políticos disponiveis são insuficientes para promover uma resolução pacífica e satisfatória. Os motivos que podem acarretar em ameaças domésticas ao Estado são diversos, apresentando facetas distintas como destaca Snyder (2000) apontando por exemplo o nacionalismo e processos de democratização. Porém, se as ameaças domésticas ao Estado podem assumir contornos variados, estas apresentam um denominador comum: a desesperança em relação ao arranjo político vigente.

A questão central, como ressalta Tilly (1984), encontra-se na distinção crucial entre o uso legítimo ou ilegítimo da força. Contudo, como este autor destaca, esta distinção apresenta duas características: é "impraticável" e "obscurante". É impraticável pois o único aspecto a 
separar as ações legítimas das ilegítimas reflete um julgamento político. É obscurante porque separa fenômenos que compartilham de muitos aspectos em comum e emergem de condições similares.

No que se refere especificamente aos gastos militares, a origem da ameaça ao Estado é irrelevante. As mesmas armas e munições que são adquiridas para serem utilizadas contra um inimigo externo também podem ser utilizadas contra adversários domésticos. Todavia, o ponto que queremos destacar é que os agentes encarregados do governo do Estado estão necessariamente obrigados a contemplarem ambas dimensões simultaneamente. Em outras palavras, os agentes dos Estados não estão limitados a somente enfrentar as pressões da estrutura do sistema internacional. Estes mesmos agentes também enfrentam pressões da estrutura doméstica do Estado. A estrutura interna do Estado também pode ser pensada como geradora de um dilema de segurança que impele os agentes encarregados do governo a reproduzir o Estado de maneira particular. Governantes estão cientes de que o tecido do Estado pode ser destruído não somente por forças externas, mas também por forças internas. Para permanecerem no poder, estes agentes têm que administrar ao mesmo tempo as restrições impostas pelas estruturas externa e interna. Uma vez que se aceite que os agentes do Estado são pressionados por ambas estruturas, é possível compreender por que a estrutura anárquica do sistema internacional nem sempre irá gerar unidades homogêneas.

Conforme foi visto, para Waltz e os demais autores neorealistas ou estruturais, o foco de suas análises é limitado às pressões que o sistema internacional anárquico exerce sobre os Estados. Para os defensores desta perspectiva, a política externa dos Estados é explicada como uma resposta racional às pressões externas, condicionada pela posição relativa no sistema internacional anárquico e mensurada através dos recursos de poder disponíveis que determinam a sua capacidade de ação independente, entre os quais, destacam-se os gastos militares.

Dado que o objetivo de Waltz foi o de desenvolver uma teoria sistêmica parcimoniosa da política internacional, este autor realmente não dedicou maiores considerações aos fatores pertencentes às unidades. Para tanto, Waltz se valeu da premissa da anarquia para erigir uma espécie de muro analítico com a finalidade de delimitar as esferas da política internacional e nacional. Não que Waltz ignorasse a importância do papel das unidades para se pensar a política internacional. Nas palavras do autor (1996), "qualquer teoria de política internacional requer também uma teoria de política doméstica".

As razões para tanto são evidenciadas pelo fato de que o processo de alocação de recursos públicos para o setor de defesa se dá em um ambiente caracterizado por conflitos, disputas e barganhas em função das preferências distintas por investimentos públicos por parte das lideranças políticas. Parafraseando Tilly (1991), se não se pode afirmar que a guerra provocou o surgimento da democracia, a disputa pelos recursos públicos destinados à defesa pelas elites civis certamente contribuiu para a consolidação desta. Neste sentido, destacaremos um dos arranjos institucionais para dirimir a ascendência dos militares sobre o poder civil: a pasta de defesa.

Inicialmente é importante ressaltar a necessidade fundamental para qualquer tipo de regime político de assegurar a supremacia civil sobre os militares. Se durante a Guerra Fria vigorou dois modelos de controle civil sobre os militares, o soviético e o liberal, ambos 
igualmente eficientes, no pós-Guerra Fria, com a dissolução do Pacto de Varsóvia, o modelo liberal irá predominar. Será justamente o modelo liberal de controle civil sobre os militares conforme preconizado pelo seu principal expoente teórico, Samuel Huntington, que irá revestir de sentido a democracia para o realismo.

Em termos gerais, autores realistas relegam para um segundo plano a democracia uma vez que este tipo de regime não possui nenhuma relação com a questão fundamental acerca da necessidade de sobrevivência do Estado no anárquico sistema internacional.

Contudo, de acordo com Huntington (1957), o modelo liberal de controle civil objetivo permitirá que democracias consigam simultaneamente assegurar a supremacia civil sobre os militares e maximizar a capacidade de combate das forças armadas através da especialização profissional.

De acordo com este autor, o papel da pasta da defesa cujo titular é um civil é fundamental para o desenvolvimento de um sistema balanceado e institucionalizado de controle civil sobre os militares. Será este locus institucional que constituirá o centro gravitacional para fazer convergir às questões técnicas e profissionais dos militares com a realidade econômica e financeira do Estado.

Em suma, tanto a democracia quanto o controle civil sobre os militares constituem fatores políticos domésticos fundamentais para se compreender o comportamento dos gastos militares no pós-Guerra Fria.

\section{Hipóteses}

O cenário internacional do pós-Guerra Fria é particularmente propício para investigar o impacto de fatores domésticos nos gastos militares, principalmente no que se refere a regimes políticos, por dois motivos:

a) a diminuição da insegurança global proporcionada pelo fim da rivalidade entre as duas superpotências e

b) o fato de que, pela primeira vez na história, o núcleo do sistema internacional é constituído exclusivamente por países de regimes democráticos.

Soma-se a este quadro a adoção desse tipo de regime por um grande número de países nos anos 90. Neste sentido, por exemplo, o estabelecimento de regimes democráticos em diversos países da Europa Central e do Leste e a continuação dos processos de democratização em países da América Latina reforçam a necessidade de se compreender o impacto da democracia no comportamento dos gastos militares.

As relações civis-militares constituem um fator fundamental para explicar os gastos militares, independentemente do tipo de regime político. No pós-Guerra Fria, a principal referência acerca do controle civil sobre o poder militar será o modelo liberal democrático. Como desdobramento é importante focalizar as relações civis-militares em regimes democráticos por dois motivos. 
Em primeiro, a emergência das novas democracias nos anos 90 não significa necessariamente que o princípio democrático de controle civil sobre o poder militar irá vigorar imediatamente nestes países. A maneira pela qual se deu a transição de regime, a herança histórica do envolvimento do estamento castrense na esfera política civil e a debilidade das instituições democráticas vis-à-vis às forças armadas constituem alguns dos aspectos que podem se revelar como obstáculos para que as novas democracias no pós-Guerra Fria adotem o mesmo comportamento em relação aos seus gastos militares do que as democracias consolidadas.

O segundo motivo consiste na necessidade de evidenciar as vantagens proporcionadas pela democracia em relação à dimensão da segurança do Estado. Caso contrário, regimes políticos permanecerão irrelevantes para o realismo. O marco conceitual que permitirá fazer convergir a ênfase realista por segurança com os princípios democráticos encontra-se na teoria liberal de controle civil sobre o poder militar em função da sua ênfase na profissionalização das forças armadas.

Desta forma, as minhas hipóteses acerca do comportamento dos gastos militares no pós-Guerra Fria compreendem tanto fatores políticos exógenos como também fatores políticos domésticos aos Estados. Estas hipóteses são:

\section{Tabela 1. Apresentação das hipóteses}

\begin{tabular}{c|l}
\hline H1 & Quanto menor a ocorrência de guerras e conflitos externos, menores serão os gastos militares do país. \\
\hline H2 & Quanto maior o status de potência de um Estado, maior serão seus gastos militares. \\
\hline H3 & Quanto maior o PIB de um país, maiores serão seus gastos militares. \\
\hline H4 & Quanto maior a renda per capita de um país, menores serão seus gastos militares. \\
\hline H5 & Quanto mais intensos os conflitos internos de um Estado, maiores serão os gastos militares. \\
\hline H6 & Quanto mais democrático for o país, menores serão os seus gastos militares. \\
\hline H7 & Quanto maior for controle dos militares pelos civis, menores serão os gastos militares. \\
\hline
\end{tabular}

\subsection{Teste das hipóteses}

Para testar as hipóteses utilizamos uma amostra aleatória de 61 países, compreendendo todas as regiões do planeta. Destes, 31 países apresentam aumento dos gastos militares e 30 países apresentam a diminuição dos gastos militares. Assim, estes países constituem uma amostra representativa para testarmos os determinantes políticos dos gastos militares no pósGuerra Fria.

Algumas omissões são importantes destacar, como por exemplo, a China e a Rússia. Em relação à primeira, a decisão de não incluí-la na amostra reflete a falta de confiança nas estimativas dos gastos militares deste país. Desde meados dos anos 80 as forças armadas chinesas tornaram-se um importante ator econômico. Os diversos empreendimentos gerenciados pelas forças armadas revelam-se imbricados ao restante da economia chinesa 
atual, tornando a tarefa de estimar os seus gastos militares extremamente complexa². Somamse a estas considerações o fato de que para diversos economistas os indicadores econômicos chineses também devem ser analisados com reservas³. A exclusão da Rússia de nossa amostra se deu pelo mesmo motivo. O processo turbulento de reestruturação política e econômica de uma ex-superpotência militar e os seus efeitos sobre os gastos militares ainda carecem de uma perspectiva mais clara. Os países da Europa Central e do Leste incluídos na nossa amostra possuem períodos distintos de análise. Os gastos militares da Bulgária são analisados a partir de 1991. Bielorússia, Estônia, Látvia, Georgia e Ucrânia a partir de 1993. República Tcheca e Lituânia a partir de 1994. As razões para tanto decorrem de que estes países vieram a obter autonomia em relação aos seus gastos militares em momentos diferentes.

Tabela 2. Países da amostra

\begin{tabular}{|c|c|c|c|c|c|}
\hline \multirow{2}{*}{ País } & Gastos militares & \multirow{2}{*}{ País } & Gastos militares & \multirow{2}{*}{ País } & Gastos militares \\
\hline & (variação\%) & & (variação \%) & & (variação \%) \\
\hline Peru & -24 & Canadá & -29 & Bielorússia & -59 \\
\hline Uruguai & -32 & EUA & -28 & Bulgária & -77 \\
\hline Venezuela & -41 & El Salvador & -57 & Rep. Tcheca & -8 \\
\hline Cambódia & 32 & Guatemala & -38 & Estônia & 152 \\
\hline Indonésia & 11 & Honduras & -51 & Geórgia & -46 \\
\hline Japão & 30 & México & 58 & Latvia & -9 \\
\hline Coréia do Sul & 7 & Nicarágua & -89 & Lituânia & 84 \\
\hline Malásia & 26 & Argentina & 12 & Polônia & -15 \\
\hline Filipinas & 87 & Bolívia & 4 & Romênia & -54 \\
\hline Cingapura & 32 & Brasil & 71 & Ucrânia & 327 \\
\hline Tailândia & 48 & Chile & 24 & Áustria & -3 \\
\hline Bangladeh & 20 & Colômbia & 14 & Bélgica & -27 \\
\hline Índia & 13 & Equador & 25 & Dinamarca & -1 \\
\hline Austrália & -18 & Guiana & 70 & Finlândia & 8 \\
\hline Nova Zelândia & 4 & Paraguai & 31 & França & -12 \\
\hline Alemanha & -31 & Noruega & -1 & Egito & -7 \\
\hline Grécia & 23 & Portugal & 3 & Israel & 7 \\
\hline Irlanda & 19 & Espanha & -12 & Turquia & 47 \\
\hline Itália & 5 & Suécia & -8 & Argélia & 202 \\
\hline \multirow[t]{2}{*}{ Holanda } & -17 & Suiça & -34 & Tunísia & -5 \\
\hline & & Reino Unido & -22 & & \\
\hline
\end{tabular}

2 James Mulvenon. Soldiers of Fortune. The Rise and Fall of the Chinese Military-Business Complex, 1978-1999. Yitzhak Schichor. China's Conversion: Myth and Reality.

. Tai Ming Cheung. The Chinese Army's Conversion to Supplement Defense Budgets

3 Miriam Leitão. (2004), "Por Trás do Mito". O Globo, P. 34. 


\section{Variável dependente: gastos militares}

Gastos militares não se referem somente aos orçamentos de defesa do Estado, possuindo um sentido mais amplo, que de acordo com a terminologia desenvolvida por Weber, compreende o monopólio legítimo da violência que o Estado detém. A definição de gastos militares varia consideravelmente de um Estado para outro devido às diferenças de classificação e de métodos contábeis utilizados para a elaboração dos orçamentos nacionais. Os gastos militares publicados nos documentos de orçamentos nacional podem abranger mais ou menos áreas de atuação do Estado. Desta forma, os orçamentos militares não representam necessariamente um indicador apropriado sobre os esforços militares reais dos Estados.

A dificuldade de distinguir entre as funções estreitamente civis e militares do Estado, somado as grandes diferenças encontradas na elaboração dos orçamentos nacionais, justifica os esforços feitos pelas principais organizações internacionais responsáveis por coletar, processar e publicar os dados estatísticos referentes a gastos militares, em harmonizar e clarificar a definição de gastos militares.

As principais fontes internacionais sobre gastos militares são o Fundo Monetário Internacional (FMI), que publica o World Economic Outlook (WEO) e o Government Finance Statistics (GFS); Instituto Internacional de Estocolmo para a Pesquisa da Paz (SIPRI); o Instituto Internacional de Estudos Estratégicos (IISS) e a Agência dos Estados Unidos para o Controle de Armas e de Desarmamento (ACDA), atualmente denominada de Bureau of Arms Control e vinculada ao departamento de Estado (State Department) deste país.

Porém, é necessário ressaltar a divergência em relação à metodologia utilizada pelas organizações internacionais supracitadas. Os dados da WEO e o GFS baseiam-se nas informações fornecidas pelos próprios governos dos países analisados. Uma vez que países não compartilham dos mesmos critérios em relação aos seus gastos militares e dado a possibilidade destes não possuírem interesse em revelar o montante real alocado para os esforços de defesa pelos mais diversos motivos, não consideramos estes indicadores como os mais apropriados.

Já o SIPRI e o IISS se valem das definições da Organização do Tratado do Atlântico Norte (OTAN) para elaborarem as suas estimativas. Todavia, ao contrário do SIPRI, o IISS não é transparente em relação às fontes utilizadas e apresenta diversas lacunas nas estimativas dos gastos militares dos países da nossa amostra. No ano de 2000, por exemplo, em relação aos gastos militares do Brasil, o IISS para o período entre 1990 e 1998 apresenta somente estimativas para os dois primeiros anos.

O SIPRI se vale da seguinte definição de gastos militares:

"todos os gastos correntes e de capital nas forças armadas, na administração de departamentos de defesa e outras agências governamentais envolvidas com projetos de defesa assim como projetos espaciais; os custos de forças paramilitares e policiais quando considerados treinados e equipados para operações militares; custos de pesquisa e desenvolvimento, testes e avaliações; e custos de pensões de aposentadoria de pessoal incluindo pensões para funcionários civis. Doações militares são incluidas nos gastos dos 
países doadores. Os itens excluidos são os de defesa civis, juros em dívidas de guerra e pagamentos de veteranos" 4 .

Desta forma, a minha variável dependente consiste no valor nominal dos gastos militares em dólares norte-americanos a preços de 1995, expediente adotado em diversos estudos sobre gastos militares. A fonte é o SIPRI, que monitora gastos militares desde 1969 em praticamente todos os países do mundo e ao longo dos anos adquiriu uma notável reputação pelo seu empenho e seriedade. Em relação a gastos militares, o principal objetivo do SIPRI é o de providenciar informações que possibilitem comparar no tempo e no espaço o total de recursos alocados anualmente para o setor de defesa em diferentes países. Os dados disponibilizados no portal eletrônico do SIPRI são expressos, para cada país e de acordo com o ano fiscal (o que requer certos ajustes em função das diferenças do calendário fiscal entre os países analisados), em moeda local a preços correntes e em dólares norte-americanos a preços constantes.

\section{Indicadores operacionais das variáveis independentes}

\subsection{Guerras e conflitos externos}

Para operacionalizar esta importante variável utilizamos um indicador de conflitos externos elaborado pelo PRS Group para o International Country Risk Guide. Este indicador inclui pressões externas não violentas (pressões diplomáticas, suspensão de auxílio, restrições comerciais e disputas territoriais) e pressões externas violentas (desde conflitos fronteiriços até guerras declaradas). Este indicador é elaborado a partir de três subcomponentes, cada um com valor máximo de quatro pontos ao valor mínimo de zero pontos. 0 resultado de quatro pontos indica niveis baixos de conflitos externos enquanto o resultado de zero pontos indica niveis elevados de guerras e conflitos externos. Os subcomponentes são guerra, conflitos fronteiriços e pressões externas.

Seguimos a premissa de Sandler e Hartley (1995) de que a variável independente em relação às ameaças externas deve ser defasada dado que o Estado deve sofrer primeiro a ameaça antes de respondê-la através do aumento dos gastos militares. Dado o cenário internacional relativamente pacífico do pós-Guerra Fria, a expectativa em relação a esta variável é que a diminuição na frequência de guerras e conflitos externos terá um impacto negativo nos gastos militares.

\footnotetext{
4 Apud Rémy Herrera. (1994), "Statistics on Military Expenditures in Developing Countries: Concepts, Methodological Problems and Sources". p. 15: "all current and capital expenditure on the armed forces, in the running of defense departments and other governments agencies engaged in defense projects as well as space projects; the costs of paramilitary forces and police when judged to be trained and equipped for military operations; military R\&D, tests and evaluation costs; and costs of retirement pensions of service personnel including pensions for civilian employees. Military aid is included in the expenditure of the donor countries. Excluded are items of civil defense, interest on war debts and veteran's payments".
} 


\subsection{Principais potências}

Potência, definido como a habilidade do Estado em exercer e resistir influências externas, é resultado de diversos fatores, entre eles as capacidades materiais do país. Para tanto, utilizamos o índice composto de capacidade nacional (Composite Index of National Capability - CINC) para operacionalizar esta variável que, por sua vez, é constituído por indicadores demográficos, industriais e militares. Como exemplo deste índice composto de capacidade nacional, no ano de 1990, o índice obtido pelos Estados Unidos foi de 0,141089, para o Brasil foi de 0,023275 e para El Salvador foi de 0,000716.

Se o pressuposto teórico subjacente a esta variável é de que as principais potências investiriam mais em recursos militares devido as suas maiores necessidades de segurança em função de suas relações externas mais abrangentes, no cenário internacional de caráter mais pacífico do período analisado, as principais potências não possuirão a mesma motivação em manter seus gastos militares em patamares elevados. Desta forma, a expectativa em relação a esta variável é de que o status de potência no pós-Guerra Fria não terá um impacto positivo nos gastos militares.

\subsection{Crescimento econômico}

Esta variável consiste de um indicador de renda agregada dos países, mais especificamente do Produto Interno Bruto em valores nominais indexados aos preços de dólares norte-americanos em 1995. Defasamos esta variável em função do componente incremental do PIB. A hipótese tradicional em relação a esta variável reflete a premissa teórica realista de que o crescimento econômico acarretaria num aumento dos gastos militares dos países. Ou seja, ao prosperarem Estados invariavelmente destinariam mais recursos para sua defesa. Desta forma, a expectativa em relação a esta variável é de que o crescimento econômico possui um impacto positivo nos gastos militares dos Estados.

Concordamos com os autores que, de um ponto de vista teórico, a variável independente renda é crucial. A razão para tanto decorre da premissa de que Estados, ao obterem um aumento no seu PIB passam a dispor de mais recursos para a sua defesa. Desta forma, a hipótese decorrente é de que gastos militares e PIB são positivamente relacionados e que a defesa é um bem normal cuja demanda aumenta conjuntamente com a renda. Como será visto mais adiante, mantivemos esta variável em nosso modelo.

\subsection{Renda per capita}

A hipótese é de que os países com renda per capita mais elevada podem atender simultaneamente as necessidades de bem-estar social e de segurança de suas populações, enquanto os países mais pobres simplesmente não podem fazer o mesmo. Para testar esta 
hipótese, operacionalizei esta variável através da renda per capita em valores nominais indexados aos preços de dólares norte-americanos em 1995. Também defasei esta variável em função do componente incremental da renda per capita. A expectativa é de que o efeito da renda per capita nos gastos militares seja negativo, uma vez que serão os países de renda per capita mais elevada os responsáveis pela iniciativa de diminuir os gastos militares no período analisado.

\subsection{Conflitos internos}

A decisão de adicionar esta variável é decorrente da inclusão na agenda de segurança internacional do pós-Guerra Fria de questões de segurança presentes na esfera doméstica dos Estados como conflitos étnicos e movimentos separatistas. Para operacionalizar esta variável utilizei um indicador de conflitos internos elaborado pelo PRS Group para o International Country Risk Guide. Este indicador mensura os níveis de violência política nos Estados e o seu impacto real ou potencial sobre os governos. 0 nível mais elevado é atribuído aos países nos quais não há oposição armada ou civil aos governos que, por sua vez, não se valem de violência arbitrária, direta ou indiretamente, contra a sua própria população. O nível mais baixo é atribuído aos países em guerra civil. 0 efeito esperado desta variável nos gastos militares é de que seja positivo, ou seja, quanto maiores forem os níveis de conflito interno de país, maiores serão seus gastos militares no período em tela.

\subsection{Democracia}

O estudo da democracia constitui uma das questões centrais para a ciência política e é crescente nesta disciplina o uso de métodos estatísticos sofisticados para desenvolver inferências causais. Para tanto, pesquisadores possuem uma ampla gama de indicadores de democracia disponíveis. Contudo, como Munck e Verkuilen (2002) irão demonstrar, alguns indicadores são melhores do que outros.

Segundo estes autores, o primeiro desafio na elaboração de um indicador de democracia consiste na complexa tarefa de conceptualização, ou seja, determinar quais são os atributos constitutivos do conceito. Neste sentido, dada a inexistência de uma maneira "correta" de especificar um conceito, indicadores de democracia podem ser desmembrados entre aqueles que a especificam através de atributos excessivos, o caso das definições maximalistas, e aqueles que procuram se valer de definições minimalistas. Em relação às definições maximalistas, o excesso de atributos pode diminuir a sua utilidade ao transformá-lo em um conceito que não possui referências empíricas ou que seja de alcance analítico curto. Definições minimalistas permitem aos pesquisadores a inclusão de um número maior de casos em suas investigações empíricas, mas com o risco de omissões de atributos relevantes para a definição do conceito.

Um exemplo de um índice de democracia que utiliza definições minimalistas é o elaborado por Tatu Vanhanen (2000). Este autor constrói o seu índice de democracia a partir de dois atributos: competição e participação política. Competição é mensurada pela percentagem obtida 
pelos partidos políticos menores em eleições para o parlamento e/ou executivo. Participação é mensurada através da percentagem da população que votou na mesma eleição. As variáveis de competição e participação são combinadas em um índice de democratização através da multiplicação de ambas percentagens e pela divisão do produto por 100.

Um exemplo de um indicador de democracia que utiliza definições maximalistas é o desenvolvido pela Freedom House. Este indicador avalia os quesitos de direitos políticos e de liberdades civis separadamente em uma escala de 1 a 7 , no qual 1 representa os casos mais livres e 7 os menos livres. A elaboração do índice é realizada através das respostas obtidas em uma lista de componentes e pelo julgamento da equipe responsável pelo índice. Através da média obtida para os direitos políticos e para as liberdades civis, os países são divididos em três categorias: livres, parcialmente livres e não livres.

Contudo, como destacam Munck e Verkuilen (2002), o indicador de democracia desenvolvido pela Freedom House apresenta um número excessivo de componentes em seus dois atributos. Em relação aos direitos políticos, este indicador apresenta 9 componentes e no atributo de liberdades civis, apresenta 13 componentes. Segundo estes autores, o principal problema deste indicador é decorrente da ausência de uma reflexão acerca da inter-relação entre os componentes e da inter-relação entre os componentes e os atributos de democracia.

Para operacionalizarmos esta variável utilizamos o Polity IV Project, que apresenta a definição de atributos de democracia de maneira mais equilibrada. Para tanto, este indicador se concentra nas características institucionais da democracia. O nível de democracia é obtido através de uma escala de 10 pontos derivado da codificação da competitividade da participação política (1-3), da competitividade do recrutamento executivo (1-2), da abertura do recrutamento executivo (1) e das restrições ao chefe de governo (1-4). Da mesma forma, o Polity IV mensura a autocracia através de uma escala de 10 pontos que verifica a ausência de competição política regulamentada (1-2), a regulamentação da participação política (1-2), a ausência de competitividade no recrutamento executivo (2), a ausência de abertura no recrutamento executivo (1) e ausência de restrições à atuação do chefe de governo.

$\mathrm{O}$ Polity IV oferece um índice único que reúne ambos indicadores, o polity 2 desenvolvido especificamente para análises de séries temporais. A nossa expectativa é de que no pós-Guerra Fria o impacto de regimes democráticos nos gastos militares seja negativo.

\subsection{Relações civis-militares}

Relações civis-militares apresentam-se como um desafio considerável para serem operacionalizadas. As razões para tanto espelham as divergências entre acadêmicos de como definir e mensurar este fator crucial para qualquer tipo de governo. Soma-se a esta observação de que nem sempre é transparente o que é uma crise nas relações civis-militares ou o que pode ser uma disputa intra-civis, um conflito intra-militares ou um embate entre facções de civis aliados de segmentos das forças armadas. Em segundo, não há consenso no que constituem relações civis militares "boas" ou "más". 
É claro que a ocorrência de um golpe militar sinaliza um péssimo relacionamento entre as lideranças civis depostas e os militares que subjugaram o governo. Contudo, relações civismilitares compreendem mais aspectos do que somente a ocorrência de golpes militares. Neste sentido, por exemplo, Desch (1999) argumenta que a influência de militares nos debates políticos nacionais não necessariamente representa um problema nas relações civis-militares, caso as forças armadas possuam um interesse e uma expertise substancial no tópico em pauta. Este autor também não considera que a frequência de conflitos entre lideranças civis e militares constitui um bom indicador, uma vez que conflitos são inevitáveis e até potencialmente benéficos em sistemas políticos plurais.

Uma maneira de operacionalizar esta variável é através da elaboração de um indicador da presença de militares na política. Esta abordagem é utilizada pelo PRS Group para o International Country Risk Guide. Dado que militares não são eleitos, qualquer envolvimento destes na esfera política, mesmo que periférico, representa uma diminuição nos níveis de democracia. Contudo, conforme o próprio PRS Group ressalta, em alguns casos a participação de militares no governo pode ser um sintoma de dificuldades inerentes a processos de transição para regimes democráticos e não a causa.

Desta forma, para operacionalizarmos este fator, nos valemos de uma variável dicotômica constituída por titulares da pasta de defesa civis, isto é, consideramos o valor 1 para ministros civis e de 0 para ministros militares. De acordo com o modelo liberal de controle civil proposto por Huntington, ministérios de defesa constituem um locus institucional em regimes democráticos voltados para a administração das relações civis-militares, ou seja, constituem um centro gravitacional onde as expectativas de atores mais ou menos independentes convergem. A análise de ministérios de defesa providencia uma perspectiva indireta acerca das relações civis-militares nos países, e esta, por sua vez, pode constituir uma maneira eficaz para verificar o funcionamento destas relações através dos níveis de colaboração e de conflitos entre lideranças civis e militares neste espaço institucional. Conforme destaca Bland (1999) esta ênfase no papel de ministérios e secretarias de defesa como fator crucial para o desenvolvimento de um sistema balanceado de relações civis militares permanece como elemento fundamental na literatura contemporânea acerca do controle civil sobre as forças armadas.

O efeito esperado desta variável é de que ministérios de defesa encabeçados por civis terão um impacto negativo nos gastos militares. Nos casos dos países em que houve alterações na titularidade da pasta ao longo do ano, consideramos como civis os ministérios que apresentaram titulares civis por mais tempo. Ou seja, se um civil permaneceu à frente da pasta de defesa por mais tempo que um militar durante o ano examinado, o ministério foi considerado como civil. Os 49 países que compõe a amostra de ministérios de defesa são: 
Tabela 3. Amostra ministros de defesa

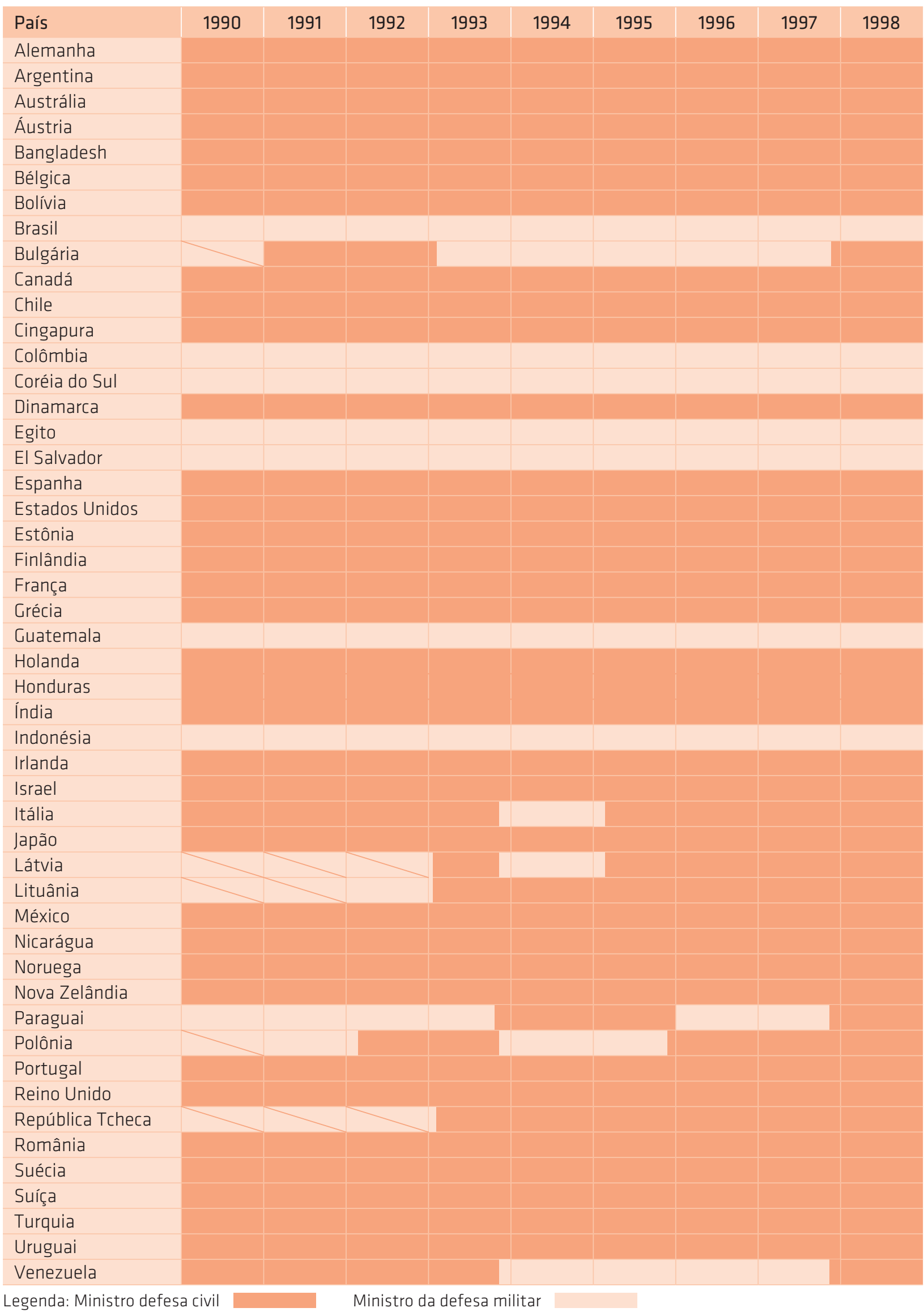


Tabela 4. Estatística descritiva básica das variáveis

\begin{tabular}{|c|c|c|c|c|}
\hline Variável & Média & Desvio padrão & Valor Máximo & Valor Mínimo \\
\hline Log Gastos militares & 7.4 & 2.1 & 12.8 & 1.1 \\
\hline Conflitos internos* & 9.78 & 2.47 & 12 & 1 \\
\hline Conflitos externos* & 11.02 & 1.41 & 12 & 5.17 \\
\hline Log Produto Interno Bruto* & 25.12 & 1.93 & 29.74 & 19.90 \\
\hline Log Renda per capita* & 8.45 & 1.45 & 10.73 & 5.478 \\
\hline Relações civis militares* & 0.82 & 0.37 & 1 & 0 \\
\hline Democracia* & 6.87 & 4.36 & 10 & -7 \\
\hline Principais potências* & 0.01 & 0.02 & 0.15 & 0.000057 \\
\hline
\end{tabular}

Legenda: As variáveis marcadas com asterisco foram utilizadas como variáveis independentes no modelo.

Tabela 5. Fontes das Variáveis Independentes

\begin{tabular}{|c|c|}
\hline Variável & Fonte \\
\hline Conflitos externos & $\begin{array}{l}\text { International Country Risk Guide (ICRG) } \\
\text { The PRS Group }\end{array}$ \\
\hline Principais potências & $\begin{array}{l}\text { Composite Index of National Capability (CINC) } 3.0 \\
\text { Correlates of War } 2 \text { Project }\end{array}$ \\
\hline Produto interno bruto & $\begin{array}{l}\text { Fundo Monetário Internacional. The International Financial Statistics (Ifs) Database } \\
\text { and Browser on Cd-Rom. } 2000 .\end{array}$ \\
\hline Renda per capita & $\begin{array}{l}\text { Fundo Monetário Internacional. The International Financial Statistics (Ifs) Database } \\
\text { and Browser on Cd-Rom. } 2000 .\end{array}$ \\
\hline Conflitos internos & $\begin{array}{l}\text { International Country Risk Guide (ICRG) } \\
\text { The PRS Group }\end{array}$ \\
\hline Democracia & $\begin{array}{l}\text { Polity IV Project } \\
\text { Www.cidcm.umd.edu/inscr/polity }\end{array}$ \\
\hline $\begin{array}{l}\text { Relações civis-militares } \\
\text { (Ministérios de defesa) }\end{array}$ & $\begin{array}{l}\text { - Base de dados Prof. Octavio Amorim Neto } \\
\text { - Woldendorp, Jaap, Hans Keman, and Ian Budge. Party Government in } 48 \\
\text { Democracies (1945-1998). Composition - Durantion - Personnel. Dordrecht: } \\
\text { Kluwer Academic Publishers, } 2000 . \\
\text { - Correspondência eletrônica com as embaixadas do Egito, Cingapura, Nicarágua, } \\
\text { Paraguai, Indonésia e Coréia do Sul. }\end{array}$ \\
\hline
\end{tabular}


Tabela 6. Expectativas em relação aos sinais das variáveis independentes

\begin{tabular}{|c|c|}
\hline Variável Independente & Sinal Esperado da Variável \\
\hline Conflitos Externos & - \\
\hline Principais Potências & + \\
\hline Produto Interno Bruto & - \\
\hline Renda per Capita & + \\
\hline Conflitos Internos & - \\
\hline Democracia & - \\
\hline Relações civis militares & \\
\hline
\end{tabular}

\section{Modelo dinâmico de gastos militares com dados de painel}

Os métodos de dados de painel possuem como objetivo levar em consideração fatores que possuem efeitos persistentes dentro de unidades de corte seccional ao longo do tempo, mas que apresentam variação entre estas unidades. No caso deste artigo, as unidades de análise são os países da amostra e que apresentam variação no comportamento dos seus gastos militares. Desta forma, como aponta Wawro (2002) uma das vantagens de dados de painel é que, com os métodos apropriados, permite levar em consideração os efeitos de variáveis que são árduas de observar. Assim, ao focalizar na heterogeneidade individual não observada das unidades, nos permite obter estimativas melhores dos efeitos das variáveis que podem ser observadas.

A utilização de dados de painel permite a estimação de modelos que levam em conta diferenças permanentes entre os países mesmo que estas não sejam observadas. Conforme ressaltam Arellano e Bover (1990), a relevância deste ponto foi demonstrada diversas vezes através dos resultados de regressões baseadas na variação intra-individual que se revelam significativamente distintas dos resultados baseados na variação entre indivíduos. Estas discrepâncias sugerem que nas regressões de corte transversal o pressuposto ceteris paribus não se verifica, uma vez que os regressores estão correlacionados com as diferenças inobserváveis incluídas nos termos de perturbação.

Logo, a utilização de dados de painel permite verificar a diversidade de comportamentos individuais, com a existência de dinâmicas de ajustamento ainda que potencialmente distintas. Ou seja, permite tipificar a resposta de diferentes países a determinados acontecimentos, em diferentes momentos.

Soma-se a este aspecto que, de acordo com Wawro (2002), estimadores de corte seccional podem conduzir a parâmetros estimados enviesados e inconsistentes. Estimadores de corte seccional, como os de Mínimos Quadrados Ordinários (MQO) perdem as desejáveis propriedades de não enviesamento e de consistência porque pelo menos uma das variáveis explicativas no lado direito da equação de regressão estará correlacionado com os termos de distúrbios, a menos que os efeitos individuais específicos sejam observados. 
Consequentemente, para obter estimativas consistentes, os efeitos individuais precisam ser tratados. A abordagem mais comum é o de transformar a equação com o objetivo de remover os efeitos individuais específicos. Assim se elimina o problema de correlação entre a variável dependente defasada e os componentes individuais específicos nos termos de erro. Uma vez que os efeitos individuais específicos são removidos, esta transformação origina uma forma diferente de correlação entre as variáveis endógenas defasadas e os distúrbios nesta equação transformada. Para eliminar este problema, são utilizadas variáveis instrumentais.

Neste sentido, Arellano e Bond (1991) conduziram testes de especificação aplicados a um modelo dinâmico de dados de painel através do Método de Momentos Generalizados e verificaram o desempenho deste procedimento utilizando dados reais e gerados. 0 estimador do Método de Momentos Generalizados elaborado por estes autores explora de maneira ótima todas as restrições lineares de momentos que são decorrentes da premissa da inexistência de correlações seriais nos erros em uma equação que contém efeitos individuais, variável dependente defasada e que não possui variáveis estritamente exógenas.

Desta forma, a partir da adoção de uma especificação dinâmica para o modelo, tornouse imprescindivel que se adotasse um método de estimação que corrigisse os problemas de viés e inconsistência gerados pela presença de correlação entre a variável dependente defasada e o resíduo. Para tanto se utilizou o estimador de Arellano e Bond calculado pelo método de momentos generalizados (GMM), que dá o tratamento adequado para modelos de painéis dinâmicos, utilizando defasagens da variável dependente como variável instrumental.

Todavia, há problemas que podem ocorrer em modelos de dados de painel, decorrentes da violação das hipóteses sobre os resíduos, como a auto correlação dos mesmos e a heterocedasticidade. Tais violações são tratadas de forma diferentes na estimação. 0 modelo é estimado com correção para heterocedasticidade, e os resultados são inferidos tomando por base os coeficientes de primeiro estágio (one-step), seguindo as recomendações de Arellano e Bond (1991). De acordo com estes autores, quando o erro é heterocedástico, as simulações sugerem que o desvio padrão assintótico do estimador de dois estágios pode ser uma referência ruim para os testes de hipóteses. Nestes casos, a inferência baseada nos desvios padrões assintóticos dos estimadores de primeiro estágio são mais confiáveis. Desta forma, as estimativas dos coeficientes reportados serão sempre as do primeiro estágio, mas os resultados dos testes de Sargan e de auto correlação dos resíduos serão os do segundo estágio.

De acordo com Arellano (2002), o teste de Sargan é eficaz para verificar se há restrições sobre-identificadas (over-identifying restrictions) no modelo. 0 teste de Sargan, nas palavras do próprio autor, "providencia um teste de significância para a hipótese de que há uma relação entre as variáveis sugeridas com os residuos independentes de todas as variáveis instrumentais"5.

Em relação à variável gastos militares, renda per capita e crescimento econômico, utilizamos logaritmos. O modelo dinâmico de dados de painel com Método de Momentos Generalizados e estimador Arellano-Bond é o seguinte:

5 Apud. Manuel Arellano. (2002), "Sargan's Intrumental Variable Estimation and GMM." CMFI 28014, P. 12: "this provides a significance test for the hypothesis that there is a relationship between the suggested variables with a residual independent of all the instrumental variables". 


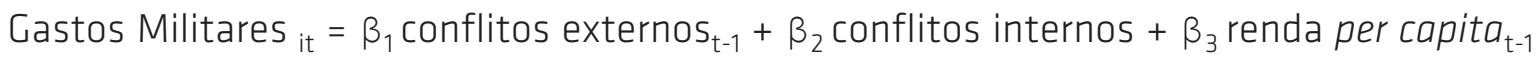
$+\beta_{4}$ crescimento econômico ${ }_{t-1}+\beta_{5}$ relações civis-militares $+\beta_{6}$ democracia $_{t-1}+\beta_{7}$ principais potências + Erro $_{i t}$

Tabela 7. Resultados GMN gastos militares, 1990-1998

\begin{tabular}{|l|c|c|}
\hline Gastos Militares (defasado) & .3402275 & $(0.000)^{* *}$ \\
\hline Principais Potências & -.0090861 & $(0.000)^{* *}$ \\
\hline Conflitos Externos & -.0001159 & $(0.937)$ \\
\hline Conflitos Internos & -.0144382 & $(0.000)^{* *}$ \\
\hline Renda per Capita & -.1546848 & $(0.000)^{* *}$ \\
\hline Produto Interno Bruto & .6975184 & $(0.000)^{* *}$ \\
\hline Relações civis militares & -.0211417 & $(0.000)^{* *}$ \\
\hline Democracia & -.0348203 & $(0.000)^{* *}$ \\
\hline Constante & -.0143341 & $(0.2988)$ \\
\hline No de observações & & $(0.0590)$ \\
\hline Teste de Sargan & chi2 $(27)=30.35$ & 1.89 \\
\hline Teste AB auto correlação 2a ordem
\end{tabular}

Nota: variável dependente: Log dos gastos militares (em milhões de US\$)

Coeficientes são estimativas Arellano-Bond com respectivos valores $p$ entre parênteses.

* significativo a $p<10 \%$, ** significativo $p<1 \%$

\section{Análise dos resultados}

Em relação ao modelo dinâmico de dados de painel com Método de Momentos Generalizados e estimador Arellano-Bond, conforme pode ser verificado pelo valor $p$ mostrado entre colchetes no teste de Sargan, a hipótese de que o modelo está sobre identificado é rejeitada, o que por sua vez atesta a validade dos instrumentos adotados na estimação. Somase a este ponto que as estimativas obtidas são consistentes, uma vez que a hipótese nula de auto correlação de segunda ordem dos resíduos não pode ser rejeitada. Em suma, o modelo dinâmico selecionado para realizar a análise é apropriado.

A hipótese de que os gastos militares possuem um componente incremental foi corroborada no modelo. Os gastos militares defasados de fato possuem um impacto positivo e robusto nos gastos militares correntes. De acordo com os resultados obtidos no modelo, o aumento de $1 \%$ dos gastos militares passados representam um incremento de $0.34 \%$ nos gastos militares presentes. Uma explicação plausível para tanto se encontra justamente nos reflexos da transformação sistêmica provocados pelo fim da Guerra Fria. Em função das mudanças na arena internacional, em um período relativamente curto de tempo, Estados modificaram rapidamente o seu comportamento em relação aos seus gastos militares. 
Em relação aos fatores externo, a primeira e mais importante variável independente é a que procura testar o impacto de guerras e conflitos externos nos gastos militares. Apesar de intuitivo, diversas análises de gastos militares não incluem este importante controle em seus modelos. No pós-Guerra Fria, em função da redução das tensões na esfera de segurança internacional, a hipótese de que neste cenário a variável guerras e conflitos externos não apresentaria o mesmo comportamento foi corroborada e os resultados obtidos revelam que esta variável não é significativa no período analisado.

Ainda em relação aos fatores externos dos determinantes dos gastos militares, no modelo a variável independente referente às principais potências correspondeu a hipótese elaborada para este fator. De fato, no cenário internacional atipicamente pacífico do imediato pós-Guerra Fria, os gastos militares das principais potências vieram a apresentar o sinal negativo esperado e se revelou significativo. Entretanto, é importante ressaltar que a posição do país no ranking de principais potências não possui um efeito substantivo relevante. De acordo com o coeficiente obtido para esta variável, o aumento de uma unidade na posição do país no ranking de principais potências no pós-Guerra Fria é responsável pela redução somente de $0.009 \%$ dos gastos militares.

Este resultado suscita questões importantes para o pensamento realista contemporâneo, uma vez que a tradicional relação entre as capacidades materiais do Estado, conforme operacionalizada através do indice composto de capacidade nacional (Composite Index of National Capability - CINC) não corresponde necessariamente ao conceito de poder nacional no pós-Guerra Fria. Em outras palavras, este conceito deve ser expandido além das capacidades materiais do Estado, ressaltando conforme Rose (1998) que o impacto dos recursos de poder na política externa dos Estados é indireto e complexo, uma vez que as pressões sistêmicas são filtradas através de variáveis intervenientes nos níveis das unidades.

Em relação às variáveis independentes referentes aos fatores domésticos do Estado, com a exceção da variável conflitos internos, os demais resultados obtidos confirmam as principais hipóteses.

A expectativa de que a variável conflitos internos viria a possuir um sinal positivo no coeficiente em função da inclusão na agenda de segurança internacional do pós-Guerra Fria de novos tópicos como por exemplo, a demanda por autonomia política de movimentos separatistas, não foi correspondida. Apesar de se revelar significativa, a variável conflitos internos apresentou um sinal negativo em seu coeficiente. Ou seja, o efeito substantivo desta variável seria o de reduzir os gastos militares em $0.014 \%$, o que simplesmente não faz sentido. Uma razão plausível para este resultado é de que os conflitos internos capazes de afetar os gastos militares são restritos a alguns poucos países e para a maioria este fator não possui o mesmo impacto.

Já no que se refere a variável crescimento econômico, de acordo com a hipótese realista de que Estados ao aumentarem a sua riqueza irão canalizar mais recursos para a defesa, foi corroborada. Conforme a expectativa, esta variável apresentou o sinal positivo esperado e se revelou significativa. É importante ressaltar que esta variável revelou um efeito substantivo extremamente elevado. De acordo com os coeficientes obtidos, o crescimento de $1 \%$ do Produto Interno Bruto acarreta no aumento de $0.70 \%$ dos gastos militares no período do pós-Guerra Fria.

A hipótese de que os países com renda per capita mais elevada possuem condições de satisfazer tanto a demanda por bens sociais como também por segurança, ao contrário dos países 
em vias de desenvolvimento, apresentou o comportamento esperado para o período analisado e revelou-se significativa ao nível de 10\%. De fato no pós-Guerra Fria o incremento de $1 \%$ na renda per capita irá decrescer os gastos militares em $0.15 \%$. Em outras palavras, os países com maior renda per capita tendem a apresentar decréscimo dos gastos militares no período analisado.

A variável democracia apresentou o sinal negativo esperado e se revelou significativa. No imediato pós-Guerra Fria os regimes democráticos irão possuir um impacto negativo nos gastos militares. Nos anos 90 o aumento de uma unidade na escala de democracia do polity IV representa uma diminuição de $0.035 \%$ nos gastos militares.

A principal contribuição desta pesquisa em relação aos fatores políticos domésticos dos determinantes dos gastos militares fez-se através da inclusão do fator relações civis-militares. Para tanto, a hipótese de que os países nos quais os titulares dos ministérios de defesa são civis teria um impacto negativo nos gastos militares no período em tela foi comprovada. Conforme a minha expectativa, esta variável apresentou o sinal negativo esperado e revelou-se significativa.

Em suma, esta análise quantitativa procurou contribuir para o desenvolvimento de uma perspectiva mais rica em relação aos determinantes políticos dos gastos militares. Através deste expediente, procurei reforçar o ponto central deste artigo de que a iniciativa de fazer convergir fatores políticos pertencentes às esferas externa e doméstica do Estado em estudos de política internacional constitui uma linha de pesquisa promissora e requer mais investigações.

\section{Conclusão}

Os resultados obtidos corroboraram o nosso argumento central. O comportamento dos gastos militares no pós-Guerra Fria é influenciado por fatores externos e domésticos do Estado.

Em relação aos fatores externos, sem sombra de dúvida a ocorrência de guerra e de conflitos entre Estados é a mais importante. Goldsmith (2003) verificou que no turbulento século XX guerras irão possuir um impacto positivo nos gastos militares. Contudo, ao contrário deste autor, a nossa hipótese era de que no cenário atipicamente pacífico do pós-Guerra Fria esta variável não iria apresentar o mesmo comportamento do que no período analisado por Coldsmith (2003). De fato, nos anos 90, com a diminuição na frequência de guerras, Estados também irão diminuir seus gastos militares. Neste sentido, este comportamento ocorrerá independentemente do status do país na hierarquia do sistema internacional. Ao contrário de Coldsmith (2003), que não obteve resultados satisfatórios para esta variável, no nosso modelo, o comportamento dos gastos militares dos países não será afetado pela sua posição no ranking de potências da arena internacional.

Todavia, os resultados obtidos mais significativos são referentes à esfera doméstica do Estado. Em relação aos fatores econômicos verificamos que o crescimento econômico dos Estados irá acarretar em mais gastos militares no pós-Guerra Fria. Desta forma, no cenário internacional dos anos 90, comprova-se a premissa realista clássica de que a defesa é um bem comum que aumenta conjuntamente com a renda do Estado.

Já em relação aos determinantes políticos domésticos, os resultados obtidos reforçam os encontrados por Goldsmith (2003). No pós-Guerra Fria, como no período analisado por este 
autor, regimes democráticos irão possuir um impacto negativo nos gastos militares. Soma-se aos determinantes políticos domésticos a nossa contribuição de adicionar uma hipótese relativa ao controle civil sobre os militares. Neste sentido, a nossa hipótese de quanto maior for controle dos militares pelos civis, menores serão os gastos militares também foi comprovada.

Os resultados obtidos através da análise econométrica dos determinantes dos gastos militares no pós-Guerra Fria proporcionam importantes subsídios teóricos acerca da relevância da agenda de pesquisa realista que procura fazer convergir as esferas externa e interna em estudos de política internacional. Através desta análise de caráter sistemático e unificado, verificamos que a teoria de política internacional de Waltz, ao focalizar exclusivamente nos fatores externos, se revela insuficiente para compreender o comportamento dos gastos militares no período analisado, sendo necessário, portanto, também incluir fatores pertencentes à esfera doméstica do Estado. Neste sentido, também verificamos que o tipo de regime político é fundamental. Ao contrário da crença realista que regimes políticos não possuem qualquer relevância em relação a fenômenos na arena internacional, comprovamos que democracia é uma variável crucial para o comportamento dos gastos militares. Em outras palavras, o tipo de regime político possui um efeito significativo no principal indicador de poder para o pensamento realista: as capacidades militares do Estado.

Contudo, se verificamos que regimes políticos, mais especificamente a democracia, são um fator importante para se compreender o comportamento dos gastos militares, esta variável por si só não nos permite incorporar à análise um fator fundamental preconizado pelo pensamento realista: a dimensão da segurança do Estado.

Será justamente neste sentido que se verifica a importância da inclusão da variável acerca do controle civil sobre o poder militar. Independentemente do tipo de governo, as lideranças políticas precisam assegurar a subordinação das forças armadas. As razões para tanto são decorrentes do fato de que, caso contrário, as forças armadas constituem uma ameaça permanente para o governo. Por outro lado, a supremacia civil sobre as forças armadas não pode comprometer a capacidade operacional e tática das forças armadas, pois neste caso o que se encontra em risco não é somente o governo, mas a própria existência do Estado. Em outras palavras, o controle civil sobre as forças armadas implica simultaneamente em assegurar a subordinação destas às lideranças política civis e maximizar a capacidade das forças armadas em desempenharem as suas funções.

\section{Bibliografia}

Alves, Vágner Camilo. 2002. O Brasil e a Segunda Guerra: história de um envolvimento forçado. São Paulo: Loyola.

2007. Da Itália à Coréia: decisões sobre ir ou não à guerra. Belo Horizonte: Ed. UFMG

Allison, Graham T. 1971. Essence of Decision. Explaining the Cuban Missile Crisis. Boston: Little, Brown and Company.

Arellano, Manuel. 2002. "Sargan's Intrumental Variable Estimation and GMM." CMFI no. 28014. 
Manuel, and S. Bond. 1991. "Some tests of specification for panel data: Monte Carlo evidence and an application to employment equations." The Review of Economic Studies no. 58:277-297.

Manuel, and Olympia Bover. 1990. "La Econometria de Datos de Panel." Investigaciones Económicas no. XIV (1).

Avant, Deborah. 1993. "The Institutional Sources of Military Doctrine: Hegemons in Peripheral Wars." International Studies Quarterly no. 37 (4):409-430.

Ayoob, Mohammmed. 1995. The Third World Security Predicament: State Making, Regional Conflict, and the International System. London: Lynne Rienner.

Baldwin, David. 1979. "Power Analysis and World Politics: New Trends versus Old Tendencies." World Politics no. 31:161-195.

David, ed. 1993. Neorealism and Neoliberalism: the contemporary debate. New York: Columbia University Press.

Barany, Zoltan. 1997. "Democratic Consolidation and the Military." Comparative Politics no. 30 (1).

Barro, Robert. 1999. "Determinants of Democracy." Journal of Political Economy no. 107 (6):158-183.

Bartels, Larry. 1994. "The American Public's Defense Spending Preference in the Post-Cold War Era." Public Opinion Quartely no. 58 (4):479-508.

Bayoumi, Tamim; Hewitt, Daniel; Symansky, Steven. 1998. "The impact of worldwide military spending cuts on developing countries." Journal of Policy Modeling no. 20 (3):261-303.

Bland, Douglas. 1999. "A Unified Theory Of Civil-Military Relations." Armed Forces \& Society no. 26 (1).

Blomberg, S Brock. 1996. "Growth, political instability and the defence burden." Economica no. 63 (252):649-672.

Bobrow, Davis, and Stephen Hill. 1991. "Non-Military Determinants of Military Budgets: The Japanese Case." International Studies Quarterly no. 35 (1):39-61.

Bowsher, Clive. On Testing Overidentifying Restrictions in Dynamic Panel Data Models. 2000. Oxford: Nuffield College, University of Oxford.

Buzan, Barry, Charles Jones, and Richard Little. 1993. The Logic of Anarchy: Neorealism to Structural Realism. New York: Columbia University Press.

Campbell, John, and Ove Pedersen. 2001. "Introduction. " In The Rise of Neoliberalism and Institutional Analysis, edited by John Campbell and Ove Pedersen. Princeton: Princeton University Press.

Cawthra, Gavin. 1997. Securing South Africa's Democracy. Defence, Devlopment and Security in Transition. New York: St.Martin's Press.

Centeno, Miguel. 1997. "Blood and Debt." American Journal of Sociology no. 102 (6):1565-1605.

Cox, Robert. 1986. "Social Forces, States and World Orders: beyond international relations theory." In Neorealism and its Critics, edited by Robert Keohane. New York: Columbia University Press.

Creveld, Martin. 1991. The Transformation of War. New York: The Free Press. 
Dahlberg, Maltz, Eva Johansson, and Per Tovmo. Power properties of the Sargan test in the presence of measurament errors in dynamic panels. 2002. Uppsala: Upssala University.

Deger, Saadet. 1986. "Economic Development and Defense Expenditure." Economic Development and Cultural Change no. 35 (1):179-96.

Saadet. 1986. Military Expenditure in Third World Countries: The Economic Effects. London: Routledge \& Kegan Paul.

DeRouen, Karl. 1995. "The Indirect Link: Politics, the Economy, and the Use of Force." The Journal of Conflict Resolution no. 39 (4):671-695.

Desch, Michael. 1999. Civilian Control of the Military. The Changing Security Environment. Baltimore: The John Hopkins University Press.

Diniz, Eli. 1998. "Globalização, Ajuste e Reforma do Estado: Um Balanço da Literatura Recente." Revista Brasileira de Informação Bibliográfica em Ciências Sociais (45):03-25.

Evans, Paul. 1998. "Using Panel Data to Evaluate Growth Theories." International Economic Review no. 39 (2):295-306.

Eyal, Jonathan, and Ian Anthony. 1988. Warsaw Pact Military Expenditure. Surrey: Jane's Information Group.

Farcau, Bruce. 1996. The Transition to Democracy in Latin America: The Role of the Military. Westport: Praeger.

Finer, S.E. 1962. The Man on Horseback. The Role of the Military in Politics. Oxford: Pall Mall Press.

Franko, Patrice. 1994. "De Facto Demilitarization: Budget-Driven Downsizing in Latin America." Journal of Interamerican Studies and World Affairs no. 36 (1):37-74.

Garfinkel, Michelle. 1994. "Domestic Politics and International Conflict." The American Economic Review no. 84 (5):1294-1309.

Geller, Daniel, and J.David Singer. 1998. Nations at War: A Scientific Study of International Conflict. Cambridge: Cambridge University Press.

Gilbert, Alan. 1992. "Must Global Politics Constrain Democracy? Realism, Regimes, and Democratic Internationalism." Political Theory no. 20 (1):8-37.

Gilpin, Robert. 1975. U.S Power and the Multinational Corporation. New York: Basic Books.

Robert. 1981. War and Change in World Politics. Cambridge: Cambridge University Press.

Robert. 1986. "The Richness of the Tradition of Political Realism." In Neorealism and its Critics, edited by Robert Keohane. New York: Columbia University Press.

Robert. 2001. Global Political Economy. Understanding the International Economic Order. Princeton: Princeton Universty Press.

Glaser, Charles. 1995. "Realists as Optimists." In The Perils of Anarchy. Contemporary Realism and International Security, edited by M.Brown, S.Lynn-Jones and S.Miller. Cambridge: The MIT Press.

Goldsmith, Benjamin. 2003. "Bearing the Defense Burden, 1886-1989." The Journal of Conflict Resolution no. 47 (5):551-573. 
Goldsmith, Benjamin. 2003. Democracy and the Defense Burden: Do democracies spend less on the military? Paper read at Anual Meeting of the American Political Science Association, at Philadelphia.

Gordon, Sandy. 1992. "Indian Defense Spending: Treading Water in the Fiscal Deep. " Asian Survey no. $32(10): 934-950$.

Gowa, Joanne. 1994. Allies, Adversaries, and International Trade. Princeton: Princeton University Press.

Haass, Richard. 1999. Intervention. The use of American military forces in the post-cold war world. Washington, D.C: Brookings Institution Press.

Halliday, Fred. 1995. "The End of the Cold War and International Relations: some analytical and theoretical conclusions." In International Relations Theory Today, edited by Ken Booth and Steve Smith. Pennsylvania State University.

Hardy, Melissa. 1993. Regression with Dummy Variables. Bevery Hills: Sage.

Hartley, Thomas, and Bruce Russet. 1992. "Public Opinion and the Common Defense: Who Governs Military Spending in the United States?" The American Political Science Review no. 86 (4):905-915.

Herrera, Rémy. 1994. Statistics on Military Expenditures in Developing Countries: Concepts, Methodological Problems and Sources. Paris: Organization for Economic Cooperation and Development.

Herspring, Dale. 1999. "Samuel Huntington and Communist Civil Military Relations." Armed Forces \& Society no. 24 (4).

Hewitt, Daniel P. 1991. "Military Expenditures in the Developing World." Finance \& Development no. 28 (3). Daniel P. 1991. "What Determines Military Expenditures?" Finance \& Development no. 28 (4). Daniel P. 1996. "Military expenditures 1972-1990: The reasons behind the post-1985 fall in world military spending." Public Budgeting and Financial Management no. 7 (4).

Hippel, Karin von. 2000. Democracy by Force. US Military Intervention in the Post-Cold War World. Cambridge: Cambridge University Press.

Huntington, Samuel. 1957. The Soldier and the State: The Theory and Politics of Civil-Military Relations. New York: Vintage Books.

Islam, Nazrul. 1995. "Growth Empirics: A Panel Data Approach." The Quarterly Journal of Economics no. $110(4): 1127-1170$.

Janowitz, Morris. 1971. The Professional Soldier: A Social and Political Portrait. New York: Free Press.

Kapstein, Ethan. 1995. "Is Realism Dead? The domestic sources of international politics." International Organization no. 49 (4).

Kemp, Kenneth, and Charles Hudlin. 1992. "Civil Supremacy over the Military: it's nature and limits." Armed Forces and Society no. 19 (1).

Krasner, Stephen. 1984. "Aproaches to the State: Alternative Conceptions and Historical Dynamics." Comparative Politcs no. 16 (2). 
Stephen. 1992. "Realism, Imperialism, and Democracy: a Reponse to Gilbert." Political Theory no. 20 (1):38-52.

Lahera, Eugenio, and Marcelo Ortúzar. 1998. "Gasto militar y el desarrollo en América Latina." Revista de la Cepal (65).

Layne, Christopher. 1994. "Kant or Cant. The Myth of the Democratic Peace." International Security no. $19(2): 5-49$.

Lebow, Richard. 1994. "The Long Peace, the end of the cold war, and the failure of realism." International Organization no. 48 (2).

Lemke, Douglas. 2002. Regions of War and Peace, Cambridge Studies in International Relations. Cambridge: Cambridge University Press.

Levi, Margaret. 1988. Of Rule and Revenue. Berkeley: University of California Press.

Mansfield, Edward, and Jack Snyder. 1995. "Democratization and the Danger of War." International Security no. 20 (1):5-38.

McKibbin, Warwick J and Thurman, Stephan. The Impact on the World Economy of Reductions in Military Expenditures and Military Arms Exports. 1993. Washington: Brookings Discussion Papers in International Economics.

McNamara, Robert. 1991. "Reducing Military Expenditures in the Third World." Finance \& Development no. 28 (3).

Milner, Helen. 1993. "The Assumption of Anarchy in International Relations Theory: a critique." In Neorealism and Neoliberalism. The Contemporary Debate, edited by David Baldwin, 144-169. New York: Columbia Universtiy Press.

Morgenthau, Hans. 1978. Politics Among Nations. The struggle for power and peace. New York: Alfred A. Knopf.

Morrow, James. 1993. "Arms versus Allies: Trade-Offs in the Search for Security." international Organization no. 47 (2):207-233.

Moskos, Charles, John Allen Williams, and David Segal. 2000. "Armed Forces after the Cold War." In The Postmodern Military: Armed Forces After the Cold War, edited by Charles Moskos, John Allen Williams and David Segal. Oxford: Oxford University Press.

Mueller, John. 1989. Retreat from Doomsday: The Obsolescence of Major Wars. New York: Basic Books.

Munck, Geraldo, and Jay Verkuilen. 2002. "Conceptualizing and Measuring Democracy. Evaluating Alternative Indices." Comparative Politcal Studies no. 35 (1):05-34.

Palmer, Glenn. 1990. "Alliance Politics and Issue Areas: Determinants of Defense Spending." American Journal of Political Science no. 34 (1):190-211.

Powell, Robert. 1994. "Anarchy in International Relations Theory: the neorealist-neoliberal debate." International Organization no. 48 (2).

Przeworski, Adam, Michael Alvarez, and Fernando Limongi. 2000. Democracy and Development. Political Institutions and Well-Being in the World, 1950-1990. Cambridge: Cambridge University Press. 
Ray, James, and Bruce Russet. 1996. "The Future as Arbiter of Theoretical Controversies: Predictions, Explanations and the End of the Cold War." British Journal of Political Science no. 26 (4):441-470.

Rose, Gideon. 1998. "Neoclassical Realism and Theories of Foreign Policy." World Politics no. 51 (1):144-172. Ruggie, John. 1995. "The False Premise of Realism.” International Security no. 20 (1):62-70.

John G. 1986. "Continuity and Transformation in the World Polity: Toward a Neorealist Synthesis." In Neorealism and its Critics, edited by Robert O. Keohane. New York: Columbia University Press.

John Gerard. 1996. Winning the Peace: America and World Order in the New Era. New York: Columbia University Press.

Russet, Bruce. 1982. "Defense Expenditures and National Well-Being." American Political Science Review (76):767-77.

Sandler, Todd, and Keith Hartley. 1999. The Political Economy of NATO. Past, Present, and into the 21st Century. Cambridge: Cambridge University Press.

Todd e Hartley, Keith. 1995. The Economics of Defense. Cambridge: Cambridge University Press.

Scheetz, Thomas. 1991. "The Macroeconomic Impact of Defense Expenditures: Some Econometric Evidence for Argentina, Chile, Paraguai and Peru." Defense Economics no. 3 (1):65-81.

Snyder, Jack. 2000. From Voting to Violence: Democratization and Nationalist Conflict. New York: W. W. Norton \& Company.

Thomson, Janice. 1994. Mercenaries, Pirates \& Sovereigns: State-building and extraterritorial violence in early modern Europe. Princeton: Princeton University Press.

Tickner, J.Ann. 1995. "Re-visioning Security." In International Relations Theory Today, edited by Ken Booth and Steve Smith. Penn State Press.

Tilly, Charles. 1975. "War Making and State Making as Organized Crime." In Bringing the State Back In, edited by Peter Evans, Dietrich Rueshenmeyer and Theda Skocpol. Cambridge: Cambridge University Press.

Charles. 1984. Big Structures Large Processes Huge Comparisons. New York: Russel Sage Foundation.

Charles. 1991. "War and State Power." Middle East Report no. 0 (171):38-40.

Charles. 1996. Coerção, Capital e Estados Europeus. São Paulo: Edusp.

Charles. 1998. "International communities, secure or otherwise." In Security Communities, edited by Emanuel Adler and Michael Barnett. Cambridge: Cambridge University Press.

Waltz, Kenneth. 1965. Man, the State and War. New York: Columbia University Press.

Kenneth. 1979. Theory of International Politics. Reading: Addison-Wesley.

Kenneth. 1986. "Reflections on Theory of International Politics: A Response to My Critics." In Neorealism and Its Critics, edited by Robert O. Keohane. New York: Columbia University Press.

Kenneth. 1990. "Realist Thought and Realist Theory." Journal of International Affairs no. 44 (1). 
Kenneth. 1993. "The Emerging Structure of International Politics." International Security no. 18 (2):44-79.

, Kenneth. 1997. "Evaluating Theories." The American Political Science Review no. 91 (4):913-917.

Wawro, Gregory. 2002. "Estimating Dynamic Panel Data Models in Political Science." Political Analysis no. 10 (1):25-48.

Wendt, Alexander. 1987. "The Agent/Structure Problem in International Relations Theory." International Organization no. 41 (335-70).

, Alexander. 1992. "Anarchy is What States Make of It: The Social Construction of Power Politics." International Organization no. 41:391-426.

Whynes, David. 1979. The Economics of Third World Military Expenditure. Austin: University of Texas Press.

Woldendorp, Jaap, Hans Keman, and Ian Budge. 2000. Party Government in 48 Democracies (1945-1998). Composition - Durantion - Personnel. Dordrecht: Kluwer Academic Publishers.

Zakaria, Fareed. 1995. "Realism and Domestic Politics." In The Perils of Anarchy. Contemporary Realism and International Security, edited by M.Brown, S.Lynn-Jones and S.Miller. Cambridge: The MIT Press.

Recebido em: 15 junho 2015

Aceito em: 06 outubro 2015 